\title{
Infected Bartholin Cyst - Ultrasonography Doppler, Magnetic Resonance Evaluation
}

\author{
Apoorvi Bharat Shah ${ }^{1}$, Suresh Vasant Phatak², Pratap Singh Parihar ${ }^{3}$, Lakshmi Bisnoi ${ }^{4}$ Gopidi Sai Nidhi Reddy ${ }^{5}$
}

1, 2, 3, 4, 5 Department of Radiodiagnosis, Jawaharlal Nehru Medical College, DMIMS, (Deemed to Be University) Sawangi, Wardha, Maharashtra, India.

\section{INTRODUCTION}

Bartholin gland cyst is the most common vulval cyst that arises from the dilated duct resulting from the obstruction of its opening. Most cysts are asymptomatic, but if not treated adequately and remain obstructed, they get infected and can result in Bartholin gland abscess. Abscess is usually present in the women of reproductive age. Patients commonly present with fever and painful progressive swelling of labia. Imaging modalities are used to diagnose the disease and it also aids to understand its extension in the complex pelvic floor region.

The vulvar region is a host of various benign and malignant lesions. Vulva is a collective term for several anatomical structures: Mons pubis, labia majora and minora, vestibule, Bartholin gland and clitoris. Most common vulva cysts are the Bartholin gland cysts. In majority of the cases, these cysts are asymptomatic or are incidentally found on imaging studies. If these cysts are not properly treated, they can get infected and cause complication such as Bartholin gland abscess. $2 \%$ of women during their lifetime develop Bartholin gland abscess or cysts. ${ }^{1}$ Pain is one of the most common indicators of infection in Bartholin cyst. Bartholin abscess starts with progressive swelling of labia majora later accompanied by fever and painful swelling of affected vulva side. ${ }^{2}$ Imaging modalities such an ultrasonography and magnetic resonance imaging aid in the diagnosis and extension of the lesion. We present a case of 55-year perimenopausal female of Bartholin gland abscesses diagnosed using imaging modalities such as ultrasound sonography (USG) and magnetic resonance imaging (MRI).

\section{PRESENTATION OF CASE}

A 55-years-old peri-menopausal woman came to AVBRH gynaecology out-patient department (OPD) with the complaint of painful swelling of her vulva on the left side since 5 days which progressed from a small sized swelling to a painful lump with overlying skin appearing erythematous. This persistent swelling was accompanied by on and off fever, difficulty in walking and pain during micturition.

On local examination, a large tender swelling was noted over the left labia with smooth shiny surface and erythema. The swelling was fluctuant and measured approximately $3 \times 2.1 \mathrm{cms}$. Vaginal wall and cervix appeared normal on per vaginum examination with no offensive discharge and a normal sized uterus with neither mass nor tenderness in pelvis. The patient later was referred to the Department of Radiodiagnosis for further evaluation. On ultrasonography, a well-defined cystic lesion with internal debris and small air foci causing dirty shadowing was seen in the region of left labia majora measuring $3 \times 2.2 \times 2 \mathrm{cms}$ showing peripheral vascularity on Doppler.
Corresponding Author: Dr. Apoorvi Bharat Shah, Arihant Hospital, Badnera Road, Nawathe Bridge, Amravati - 444605, Maharashtra, India.

E-mail: apoorvisaha1805@gmail.com

DOI: $10.14260 /$ jemds/2021/289

How to Cite This Article:

Shah AB, Phatak SV, Parihar PS, et al. Infected Bartholin cyst - Ultrasonography Doppler, magnetic resonance evaluation. J Evolution Med Dent Sci 2021;10(18):13691371, DOI: $10.14260 /$ jemds/2021/289

Submission 04-11-2020,

Peer Review 04-03-2021,

Acceptance 12-03-2021,

Published 03-05-2021.

Copyright (C) 2021 Apoorvi Bharat Shah et al. This is an open access article distributed under Creative Commons Attribution License [Attribution 4.0 International (CC $B Y 4.0)]$ 

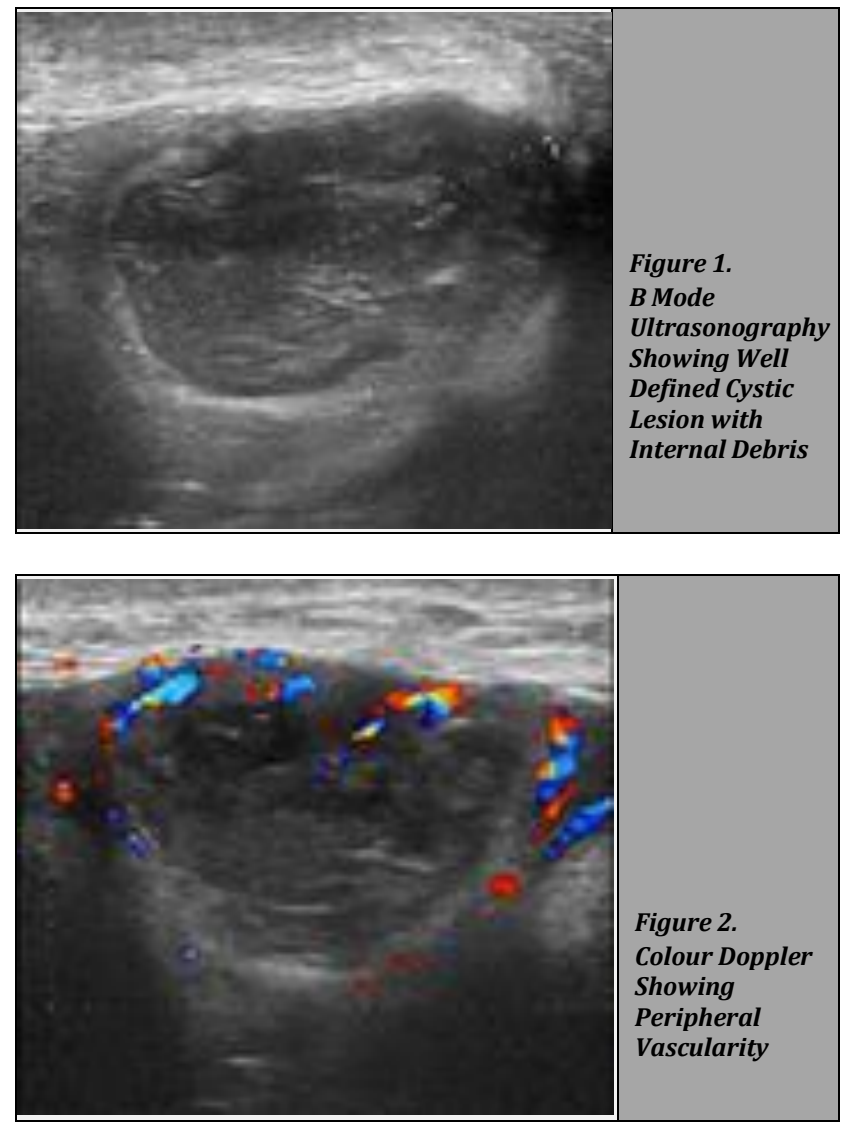

On MRI imaging, a well-defined peripherally enhancing cystic lesion of size $3 \times 2.2 \times 2 \mathrm{cms}$ was seen in left posterolateral lower third of vagina associated with labia majora. This lesion appeared heterogeneously hypo intense on T1WI, heterogeneously hyperintense on T2WI / STIR, shows few foci of blooming on graduate record examination (GRE) and restriction on diffusion weighted imaging (DWI). Left labia majora showed oedematous changes with contrast enhancement. Uterus showed an incidental finding of posterior intramural fibroid and simple cyst in left ovary.
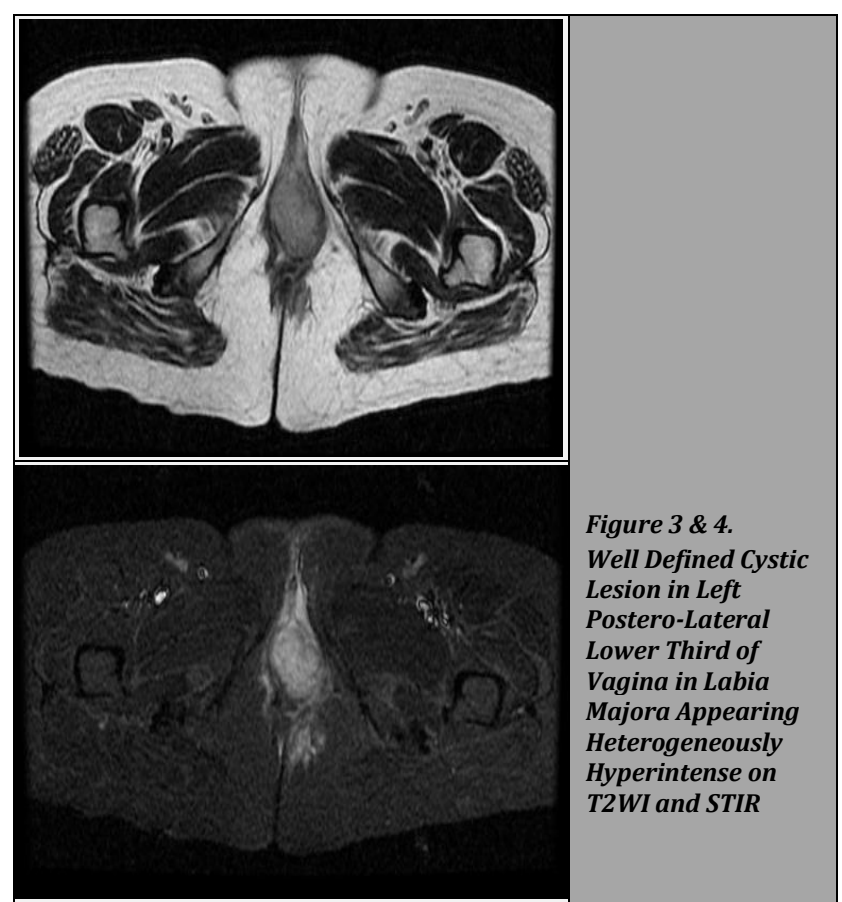

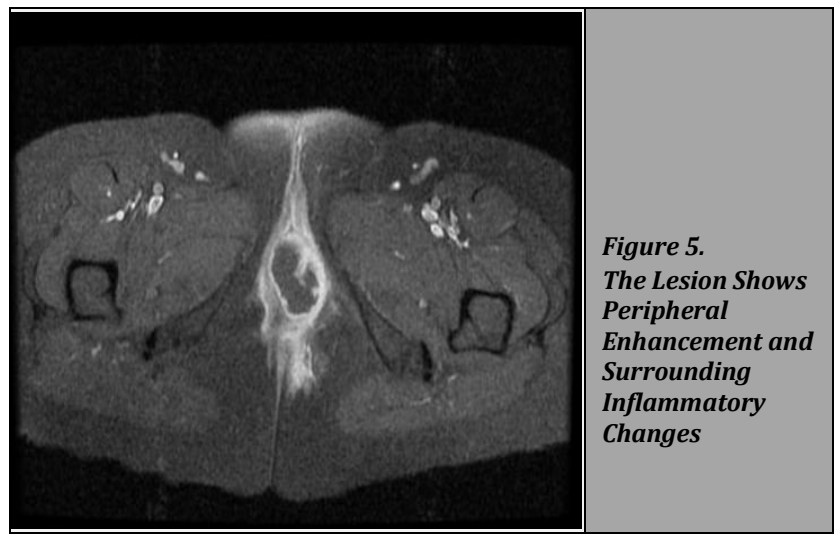

The patient was later referred to the Department of Surgery for emergency incision and drainage and the discharge was sent for histopathological correlation which confirmed the diagnosis of an abscess.

\section{DISCUSSION}

Complex structure of muscles, fascia and ligaments are present in the pelvic floor. An interischial imaginary line is drawn between the ischiopubic rami which helps in dividing the perineum in anterior urogenital triangle and the posterior anal triangle. The post anal triangle has the anal canal with external and internal sphincters, ischioanal fat-containing fossa, and neurovascular bundles. The urogenital triangle attaches to the perineal body from the pubic bones and forms a sloping triangular plane and is divided into two components, the perineal superficial pouch and the perineal membrane or urogenital diaphragm. ${ }^{1}$

Greater vestibular gland or Bartholin gland forms from the superficial perianal pouch of urogenital triangle, is a compound racemose gland. The normal measurement of the gland is approximately $0.5 \mathrm{~cm}$ with a $2 \mathrm{~cm}$ duct, lined by the columnar epithelium, and opens in the vestibule at $5^{\prime} \mathrm{O}$ and $7 \mathrm{I}^{\prime} \mathrm{O}$ clock position, in the groove between the hymen and labia minora. During sexual stimulation, it secretes alkaline mucus

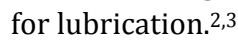

The Bartholin gland masses of cysts or abscesses are the most common. The most common vulvar cysts are the Bartholin gland cysts, ranging in size from 1 to $4 \mathrm{~cm}$, but their size increases with repeated sexual stimulation. Cyst arise from dilated duct formed secondarily to a blockage in the duct opening. An obstructed Bartholin duct is vulnerable to being infected, developing an abscess later on. Abscesses are 3 times more prevalent than cysts. ${ }^{4}$ Women are likely to experience Bartholin abscesses in the reproductive age group. ${ }^{5}$ Ductal obstruction leads to accumulation of secretions and cyst development due to prior infection or inspissated mucus. The disease is typically polymicrobial, with the main species being bacteroides and Escherichia coli. ${ }^{6}$

Bartholin abscess can be imaged with different modalities such as US, elastography, computerised tomography (CT), and MR imaging with majority presenting as cystic masses. MR imaging with its multiplane capabilities makes this modality ideal for knowing relationship of the cyst to the surrounding structures.

The overlying skin tends to be erythematous on USG and is sensitive on palpation. Instead of clear fluid, the abscess 
contains pus and appears as an echogenic fluid collection with internal echoes, occasionally containing septa and sediment. Because of the inflammatory response of the adjacent tissue, the abscess may become echogenic with less well-defined borders. ${ }^{7}$ Elastography with colour graphic representation of tissue elasticity, overlays traditional B mode imaging. Elastography is a recent addition to sonography in real time and helps to diagnose and differentiate soft tissue infections as they move from induration to fluctuating abscesses. It provides an estimation of tissue stiffness by calculating the degree of distortion applied by the ultrasonography probe under the external force. It provides a colour that displays with colour range relating to the stiffness of the tissue, similar to colour Doppler. ${ }^{8}$ MRI, is helpful in guiding treatment planning, surgical planning and excision. Abscesses occur in the vulva area as solitary unilateral welldefined lesions, display low to moderate signalling on T1weighted images, depending on the fluid's mucin content, and appear hyper-intense on T2-weighted images. In post-contrast analysis with non-enhancing center and surrounding inflammatory reaction, abscess enhances peripherally. The abscess is present inferior to perineal membrane and is well identified in sagittal images below the inferior margin of the symphysis pubis. ${ }^{7}$ On CT, near the vaginal introitus, a hypo- to hyper-attenuating abscess is seen. The presence of solid component in the abscess will be a risk for neoplastic changes. ${ }^{1}$

The differential diagnosis includes different vulvar pathologies which include epidermoid cyst, Skene's paraurethral gland cyst. The key to identifying a Bartholin's abscess is the anatomical location of the mass. The treatment of Bartholin's gland abscesses depends on the presenting symptoms that may indicate the cause of the abscess; however, if it has begun to appear asymptomatically, marsupialization may be required only without the polymicrobial antibiotic treatment being issued. For diagnosis, a pathological examination is necessary. ${ }^{2}$

Financial or other competing interests: None.

Disclosure forms provided by the authors are available with the full text of this article at jemds.com.

\section{REFERENCES}

[1] Hosseinzadeh K, Heller MT, Houshmand G. Imaging of the female perineum in adults. Radiographics 2012;32(4):E129-68.

[2] Lilungulu A, Mpondo BC, Mlwati A, et al. Recurrent huge left Bartholin's gland abscess for one year in a teenager. Case Rep Infect Dis 2017;2017:9151868.

[3] De La Noval BD, Fernández IG, Fernández BÁ. Bulky Bartholin's gland cyst: case report of an incidental finding. Case Rep Womens Health 2019;22:e00115.

[4] Omole F, Simmons BJ, Hacker Y. Management of Bartholin's duct cyst and gland abscess. Am Fam Physician 2003;68(1):135-40.

[5] Kallam AR, Kanumury V, Bhimavarapu N, et al. A report of two cases of giant Bartholin gland cysts successfully treated by excision with review of literature. J Clin Diagn Res 2017;11(6):PD11-3.

[6] Brook I. Aerobic and anaerobic microbiology of Bartholin's abscess. Surg Gynecol Obstet 1989;169(1):324.

[7] Cheung VYT. Ultrasonography of benign vulvar lesions. Ultrasonography 2018;37(4):355-60.

[8] Gaspari R, Blehar D, Mendoza M, et al. Use of ultrasound elastography for skin and subcutaneous abscesses. J Ultrasound Med 2009;28(7):855-60. 